\title{
Transitioning from a crystallographer to a structural biologist: Lessons learned John Rose ${ }^{1}$ \\ ${ }^{1}$ SER-CAT/University of Georgia jprose@uga.edu
}

\begin{abstract}
Although I had determined a number of small molecule crystal structures as a graduate student at Rutgers University making the transition to structural biology was a learning experience. I joined Bi-Cheng (B.C.) Wang's lab at the V.A. Medical Center (VA) in Pittsburgh in 1980. Note at this time the PDB contained only 69 total entries. I began my career by isolating and purifying the oxytocin/vasopressin carrier protein neurophysin (NP) from ovine posterior pituitaries; learning how to grow and mount protein crystals; mastering data collection on the Picker FACS diffractometer; and modifying the space group specific (P21212) data reduction programs in use at the VA to make them space group general and more efficient. I also adapted the LN2-based low temperature system to use chilled isopropanol $\left(-40^{\circ} \mathrm{C}\right)$ to maintain the crystal at $4^{\circ} \mathrm{C}$ during data collection. The next five years saw dramatic strides in data collection with low power tube-based generators replaced by rotating anodes and point detector systems replaced by $2 \mathrm{D}$ area detectors (film and multiwire) increasing data collection efficiency, data quality and data resolution.
\end{abstract}

Much of my time during these early years was spent searching for one heavy atom derivative. B.C. Wang was working on his ISIR/ISAS phasing package so one good heavy atom derivative was all I needed. I scanned over 100 heavy atom compounds with no luck. The NP structure was eventually solved by iodine-SAD, the first protein structure phased by Wang's Iterative Single Anomalous Scattering method, (B.C. Wang, Methods Enzymol. 115: 90-112, 1985) using inhouse data and crystals grown with p-iodo-Phe-Tyr amide. Today, neurophysin could be readily solved using sulfur-SAD.

The poster will present lessons learned during this time including Rule 1 - Never put your best crystal on first! 